\title{
Cuprous oxide nanoparticles inhibit prostate cancer by attenuating the stemness of cancer cells via inhibition of the Wnt signaling pathway
}

This article was published in the following Dove Press journal:

International Journal of Nanomedicine

31 March 2017

Number of times this article has been viewed

\author{
Ye Wangl,* \\ Qi-Wei Yang ${ }^{1,2, *}$ \\ Qing Yang ${ }^{2, *}$ \\ Tie Zhou' \\ Min-Feng Shi ${ }^{1,3}$ \\ Chen-Xia Sun ${ }^{4}$ \\ Xiu-Xia Gao ${ }^{4}$ \\ Yan-Qiong Cheng' \\ Xin-Gang Cui ${ }^{2}$ \\ Ying-Hao Sun' \\ 'Department of Urology, Changhai \\ Hospital, ${ }^{2}$ Department of Urology, \\ The Third Affiliated Hospital, \\ ${ }^{3}$ Reproductive Center, Changhai \\ Hospital, Second Military Medical \\ University, Shanghai, ${ }^{4}$ The \\ Reproductive Center, Institute \\ for Nutritional Sciences, Shanghai \\ Institute for Biological Science, \\ Chinese Academy of Science, \\ Shanghai, People's Republic of China \\ *These authors contributed equally \\ to this work
}

Correspondence: Ying-Hao Sun

Department of Urology, Changhai Hospital, Second Military Medical

University, 800, Xiangyin Road, Shanghai

200433, People's Republic of China

Tel +862181870001

Fax +86 2I 81870001

Email sunyhsmmu@|26.com

Xin-Gang Cui

Department of Urology, The

Third Affiliated Hospital, Second

Military Medical University,

800 Xiangyin Road, Shanghai 200433,

People's Republic of China

Tel +862181887823

Fax +862181887823

Email cuixingangjiaoshou@yeah.net

\begin{abstract}
Disordered copper metabolism plays a critical role in the development of various cancers. As a nanomedicine containing copper, cuprous oxide nanoparticles (CONPs) exert ideal antitumor pharmacological effects in vitro and in vivo. Prostate cancer is a frequently diagnosed male malignancy prone to relapse, and castration resistance is the main reason for endocrine therapy failure. However, whether CONPs have the potential to treat castration-resistant prostate cancer is still unknown. Here, using the castration-resistant PC-3 human prostate cancer cell line as a model, we report that CONPs can selectively induce apoptosis and inhibit the proliferation of cancer cells in vitro and in vivo without affecting normal prostate epithelial cells. CONPs can also attenuate the stemness of cancer cells and inhibit the Wnt signaling pathway, both of which highlight the great potential of CONPs as a new clinical castration-resistant prostate cancer therapy.
\end{abstract}

Keywords: cuprous oxide nanoparticle, prostate cancer, CRPC, nanomedicine, Wnt signaling pathway

\section{Introduction}

Prostate cancer is the most commonly diagnosed noncutaneous malignancy and remains the second leading cause of cancer-related death among men. Androgen deprivation therapy (ADT), the standard of care for patients with locally advanced disease, metastatic disease, or biochemical recurrence after definitive primary therapy, has been demonstrated to provide an initial benefit. ${ }^{1-3}$ Unfortunately, castration resistance predicts a more ominous outcome with a median patient survival time of 2 years. Castration-resistant prostate cancer (CRPC), previously known as hormone-refractory prostate cancer, is now understood to be a progressive of disease despite medical or surgical castration. ${ }^{4-6}$ Castration resistance has historically been defined as progression despite achieving a castrate serum testosterone level lower than $50 \mathrm{ng} / \mathrm{mL}$, which does not respond to ADT. Even though abiraterone acetate, enzalutamide, Ra-223 dichloride, and chemotherapy can be used for CRPC therapy, drug resistance often manifests in CRPC patients, and the overall survival benefit is limited. ${ }^{7-10}$ Therefore, there is an urgent need to discover new drugs.

Arsenic trioxide ${ }^{11,12}$ and Artemisia annua $\mathrm{L}^{13,14}$ are components of a popular traditional Chinese remedy that has been used to successfully treat acute promyelocytic leukemia and malaria by Chinese scientists. Inspired by this activity, our group discovered that azurite ore has been used as an antitumor medicine and recorded in Shen Nong's Herbal - a traditional Chinese medical text - and is now known to be a type of copper 
compound. With the rapid development of nanoscience and nanotechnology, nanomedicines have been emerging as a new treatment option. Combining the azurite ore and nanoscience, our research group has examined the possibility of applying cuprous oxide nanoparticles (CONPs) to cancer therapy. ${ }^{15,16}$

As CRPC is one of the possible manifestations of ADT during prostate cancer treatment and the overall survival benefit of marketed drugs is limited, it is necessary to explore the pharmacological effects of CONPs on CRPC. In addition, our previous study shows that melanoma is highly sensitive to $\mathrm{CONPs}^{15,16}$ and that melanoma and prostate cancer exhibit similar copper metabolism disorder characteristics, ${ }^{17-19}$ which suggests that CONPs may also affect prostate cancer, including CRPC.

To verify this hypothesis, we sought to test the anti-CRPC capability of CONPs in vitro and in vivo. We prepared CONPs to explore their pharmacological effects on human and mice prostate cancer cell lines, including androgendependent cell lines, CRPC cell lines, and a normal prostate epidermal cell line. We discovered that CONPs could selectively induce apoptosis and suppress the proliferation of prostate cancer cells. For the in vivo study, we established a subcutaneous prostate mouse model based on the castrationresistant PC-3 cell line. Following an intratumoral injection of CONPs into subcutaneous prostate cancer, we found that the growth of the tumors was significantly inhibited. Cancer stem cells (CSCs) are one contributor to the development of CRPC. ${ }^{20,21}$ We found that CONPs can significantly inhibit the stem-like characteristics of prostate cancer, including sphere formation, clone formation, and the expression of stemness transcription factors. In exploring the mechanism of CONPs, we found that CONPs can significantly inhibit the Wnt signaling pathway, which is important for the self-renewal and the stemness stability of stem cells. Our results strongly suggest that CONPs can ultimately be applied to treat CRPC as a new type of antitumor nanomedicine for prostate cancer therapy, especially for patients with CRPC.

\section{Materials and methods CONPs synthesis}

CONPs were synthesized according to our previously reported protocol. ${ }^{15}$

\section{In vitro cytotoxicity assay}

The PC-3 human prostate cancer cell line, LNCaP FGC cells, and the normal prostate epithelial cell line RWPE-1 were obtained from American Type Culture Collection. The human prostate cancer cell line DU145 and the mouse prostate cancer cell line RM1 were acquired from the Cell Bank of Typical Culture Collection (Chinese Academy of Sciences, Shanghai, People's Republic of China). Both these cell lines were stored in our laboratory. PC-3 cells were grown in F-12 medium (Gibco, Invitrogen Corp, Carlsbad, CA, USA). LNCaP FGC cells and DU145 cells were grown in RPMI 1640 medium. RM-1 cells were grown in Dulbecco's Modified Eagle's Medium (DMEM). RWPE-1 cells were grown in the K-SFM medium. All media used in this study were supplemented with $100 \mathrm{U} / \mathrm{mL}$ penicillin and streptomycin. RPMI 1640, DMEM, and F-12 media were also supplemented with $10 \%$ (vol/vol) heat-inactivated fetal bovine serum. The cells were maintained at $37^{\circ} \mathrm{C}$ in a humidified environment containing $5 \% \mathrm{CO}_{2}$. To evaluate the cytotoxicity of the CONPs, cells in the logarithmic growth phase were seeded onto a 96 -well culture plate at 1,000 cells per well and incubated at $37^{\circ} \mathrm{C}$ in an incubator containing $\mathrm{CO}_{2}$ for $24 \mathrm{~h}$ until the cells adhered to the plate. Serial dilutions of CONPs were then added. After 48 and $72 \mathrm{~h}$, cell viability was measured using the CCK- 8 kit. In this assay, $10 \mu \mathrm{L}$ of CCK- 8 solution and $90 \mu \mathrm{L}$ of fresh RPMI 1640 medium mixture was added to the cells and incubated for $4 \mathrm{~h}$, after which the absorbance was measured at $405 \mathrm{~nm}$ using an ELISA plate reader (Tiilitie, Vantaa, Finland). The cytotoxicity was calculated as $(\%)=[1-(\mathrm{OD}$ from tested cells)/OD from control cells] $* 100 \%$.

\section{In vitro cell invasion assays}

To explore the antimigratory effects of CONPs on the PC-3 cells, $1 \times 10^{4}$ cells were seeded on a Matrigel (R\&D Systems, Minneapolis, MN, USA)-coated polycarbonate membrane insert ( $6.5 \mathrm{~mm}$ in diameter with 8.0 -mm pores) in a 24-well culture Transwell apparatus (Costar, Cambridge, MA, USA) and cultured in F-12 media containing $0.5 \%$ fetal bovine serum. CONPs were added to the upper chamber at a final concentration of $0,1.25$, or $2.5 \mu \mathrm{g} / \mathrm{mL}$. RPMI 1640 medium supplemented with $10 \%$ fetal bovine serum was added to the lower chamber. After incubating for $48 \mathrm{~h}$ at $37^{\circ} \mathrm{C}$ in an environment containing $\mathrm{CO}_{2}$, the cells on the top surface of the insert were removed by wiping with a cotton swab. Cells that migrated to the bottom surface of the insert were fixed with paraformaldehyde, stained with crystal violet, and visually scored in five random fields using a light microscope.

\section{Apoptosis detection by annexin V/PI staining}

PC-3 cells in the logarithmic growth phase were seeded onto a six-well culture plate at a density of $1 \times 10^{5}$ cells per well 
and incubated at $37^{\circ} \mathrm{C}$ in a $\mathrm{CO}_{2}$ incubator in the presence of $1.25,2.5$, or $5 \mu \mathrm{g} / \mathrm{mL}$ CONPs. After 48 and $72 \mathrm{~h}$, apoptosis and necrosis were analyzed with the annexin $\mathrm{V}$-fluorescein isothiocyanate apoptosis detection kit following the manufacturer's instructions. The samples were analyzed using a FACSCalibur flow cytometer (Becton Dickinson, San Jose, CA, USA).

\section{Flow cytometry of cell cycle progression}

The cells were harvested with a $0.25 \%$ trypsin solution containing $1 \mathrm{mM}$ of EDTA and fixed in $70 \%$ ethanol for $12 \mathrm{~h}$ at $4{ }^{\circ} \mathrm{C}$. The fixed cells were then centrifuged at $3,000 \mathrm{rpm}$ for $15 \mathrm{~min}$ to remove the ethanol thoroughly. The cells were then washed twice with $3 \mathrm{~mL}$ of phosphate-buffered saline (PBS), resuspended in $1 \mathrm{~mL}$ of propidium iodide (PI) staining solution, and incubated for $15 \mathrm{~min}$ at room temperature. The staining solution consisted of $20 \mu \mathrm{g} / \mathrm{mL}$ PI and $0.2 \mathrm{mg} / \mathrm{mL}$ RNase A in PBS. The samples were subsequently analyzed using a BD FACSCanto flow cytometer (BD Biosciences, Franklin Lakes, NJ, USA).

\section{Self-renewing spheroid formation assay}

For the self-renewing spheroid formation assay, 2000 PC-3 cells in a single cell suspension were plated per well on a 6-well low attachment plate (Corning, Lowell, MA, USA). Cells were cultured in serum-free DMEM/F12 medium (Gibco) supplemented with $20 \mathrm{ng} / \mathrm{mL}$ human basic FGF (R\&D), $20 \mathrm{ng} / \mathrm{mL}$ human EGF (R\&D), $3 \mu \mathrm{g} / \mathrm{mL}$ insulin (Sigma, St Louis, MO, USA), and 1× B27 (R\&D), and approximately $50 \%$ of the medium was replaced every 2 days.

\section{Colony formation assay}

The colony formation assay was used to determine the selfrenewal and proliferative capacity of cells, including cancer cells and stem cells. Briefly, PC-3 cells were seeded in 10-cm dishes at a low density (approximately 1,000 cells per well) and cultured for 9 days. The plates were then washed with PBS and stained with crystal violet. The images of each well were scanned, and individual clone types were identified. We randomly selected ten different fields per dish at $400 \times$ magnification and counted the number of cell clusters comprising more than 50 cells.

\section{In vivo antitumor properties in mice with subcutaneous prostate cancer}

PC-3 cells were cultured in F-12 medium (Gibco) and suspended at $5 \times 10^{6}$ cells $/ \mathrm{mL}$ mixed with $50 \%$ Matrigel in PBS directly before injection. For the subcutaneous tumor studies, 6- to 8-week-old male nude mice were sedated with tribromoethanol (Sigma). The right hind leg was shaved before a subcutaneous injection of $100 \mu \mathrm{L}$ of the cell suspension was administered. The tumors were monitored, and treatment began when the average tumor diameter reached 5-7 $\mathrm{mm}$ after injection. The mice in the CONP treatment group were intratumorally injected with CONPs at a dose of $15 \mathrm{mg} / \mathrm{kg}$ every day, whereas the control mice were injected with the same volume of a $5 \%$ glucose solution. CONPs were dissolved in a 5\% glucose solution using an ultrasonic mixer (Bilon, Shanghai, People's Republic of China). All the observers in the studies were blinded regarding the tumor area and survival rates. Six mice per group were euthanized at different time points, and the tumors were excised and weighed. All the animal experiments were performed in accordance with the Guide for the Care and Use of Laboratory Animals and were approved by the Bioethics Committee of Second Military Medical University, and all the experiments were performed following relevant guidelines and regulations of Second Military Medical University.

\section{Terminal deoxynucleotidyl transferase (TdT)-mediated dUTP nick end labeling (TUNEL) assay}

To test for apoptosis in a subcutaneous tumor of the CONPtreated and control mice on day 16 , resected tumor tissue was fixed in 4\% paraformaldehyde for $24 \mathrm{~h}$ and then embedded in paraffin. Tissue blocks were sectioned into $3-\mu \mathrm{m}$ slices and mounted on glass slides. The TUNEL assay was then performed using an in situ cell death detection kit (Roche, Mannheim, Germany) according to the manufacturer's instructions.

\section{Immunohistochemical staining}

Immunohistochemical assays were performed on formalinfixed, paraffin-embedded sections. Polyclonal rabbit Ki-67 primary antibodies were used (CST, Danvers, MA, USA). Four-micron-thick sections on glass slides were deparaffinized in Hemo-D and rehydrated in graded alcohols followed by an endogenous peroxidase block in $3 \% \mathrm{H}_{2} \mathrm{O}_{2}$ and antigen retrieval in boiling $10 \%$ citrate buffer. Then, the slides were incubated with the polyclonal antibody against Ki-67 (1:200 dilution) overnight at $4^{\circ} \mathrm{C}$, washed three times with Tris-buffered saline containing Tween 20 (TBST, $\mathrm{pH}=7.6$ ), and subsequently treated with a horseradish peroxidase-labeled dextran polymer coupled to an antirabbit antibody (CST) for $30 \mathrm{~min}$ at room temperature. Finally, the 
slides were developed with diaminobenzidine for $10 \mathrm{~min}$ and counterstained with hematoxylin after washing three times with TBST. The specificity of the staining was confirmed by processing sections from the same paraffin block without the primary antibody treatment (negative control).

\section{Real-time RT-PCR}

To verify the effects of CONPs on important transcription factors associated with stemness maintenance, we performed real-time RT-PCR on PC-3 cells. PC-3 cells were treated with CONPs for $48 \mathrm{~h}$ at a concentration of $1.25 \mu \mathrm{g} / \mathrm{mL}, 2.5 \mu \mathrm{g} / \mathrm{mL}$, or $5 \mu \mathrm{g} / \mathrm{mL}$. Then, total RNA was extracted using TRIzol reagent (Invitrogen, USA) and purified using an RNeasy Mini column (Qiagen, Hilden, Germany) according to the manufacturer's protocols. Two micrograms of purified total RNA was reverse-transcribed to cDNA with random primers and MultiScribe Reverse Transcriptase (Applied Biosystems, Foster City, CA, USA). The relative gene expression levels were measured by real-time RT-PCR using the genespecific primers and iQ SYBR Green Supermix (Bio-Rad, Philadelphia, PA, USA) and compared with the levels of RPL13a RNA for each cDNA sample as an internal control. $\beta$-Actin was used as an endogenous RNA reference gene to normalize the expression. The primers for Oct4, Sox2, c-Myc, $K L F 4$, and $\beta$-Actin are as follows:

Oct4 (F) (5'- TTCCCCCTGTCTCCGTCAC -3'), OCT4 (R) (5' - AGAACTTAATCCCAAAAACCCTGG -3'); Sox2 (F) (5'- GACCAGCTCGCAGACCTACAT -3'), Sox2 (R) (5'- ATGGAGCCAAGAGCCATGC -3'); c-Myc (F) (5' - CAGCGACTCTGAGGAGGAACAA -3'), c-Myc (R) (5'- CCAGCAGAAGGTGATCCAGACT -3'); KLF4 (F) (5'- GCCGCTCCATTACCAAGGTCAG -3'), KLF4 (R) (5'-ATCATCCCGTGTGTCCCGAAGT -3'); $\beta$-Actin (F) (5'- CGCGAGAAGATGCCCAGATC-3'), $\beta$-Actin (R) (5'- TCACCGGAGTCCATCACGA -3').

\section{Western blotting analysis}

Briefly, PC-3 cells were treated with CONPs at a concentration of $1.25 \mu \mathrm{g} / \mathrm{mL}, 2.5 \mu \mathrm{g} / \mathrm{mL}$, or $5 \mu \mathrm{g} / \mathrm{mL}$. After treatment for $48 \mathrm{~h}$, the cells were pelleted by centrifugation and washed twice with ice-cold PBS. The resultant cell pellets were resuspended in $1 \mathrm{~mL}$ of RIPA lysis solution containing DTT and protease inhibitor and incubated for $15 \mathrm{~min}$ on ice. Then, unbroken cells and large debris were removed by centrifugation. The lysis solution isolated from the cells was loaded on a 10\% SDS-PAGE gel, followed by Western blotting with an anti-Oct4, anti-Sox2, anti-KLF4, anti-c-Myc, anti-Wnt1A, anti-Cyclin D1, anti-LC3A, anti-LC3B, anti-Atg5, anti-Atg7, and anti-Atg12 antibodies (CST). The bound antibody was detected with peroxidase-conjugated antirabbit antibody followed by chemiluminescence (ECL System, Waltham, MA, USA) and exposed by autoradiography. The same blots were reprobed for $\beta$-actin (CST) as a protein loading control.

\section{Data and statistical analyses}

The data are presented as the means \pm SD. Student's $t$-test, and ANOVA assay was used to analyze differences in tumor masses, sphere formation, plate clone formation, etc. Statistical significance was established at $P<0.05$.

\section{Results CONPs selectively induce apoptosis and the migration of prostate cancer}

CONPs were synthesized and characterized as in our previous studies, and the diameter of the CONPs used in these experiments ranged from 40 to $110 \mathrm{~nm}$. Cell viability following CONP treatment was then evaluated using the CCK8 kit. Our data showed that CONPs could cause cell death in the human prostate cancer PC-3 cell, LNCaP FGC cells, DU145 cells, and mice prostate cancer cell line RM-1 in a dose- and timedependent manner. The half maximal inhibitory concentration $\left(\mathrm{IC}_{50}\right)$ for the PC-3 cells was $6.604 \mu \mathrm{g} / \mathrm{mL}$ and $3.793 \mu \mathrm{g} / \mathrm{mL}$ after $48 \mathrm{~h}$ and $72 \mathrm{~h}$ of CONP treatment; for the LNCaP FGC cells, $0.913 \mu \mathrm{g} / \mathrm{mL}$ and $0.44 \mu \mathrm{g} / \mathrm{mL}$ after $48 \mathrm{~h}$ and $72 \mathrm{~h}$ treatment; for the DU145 cells, $3.813 \mu \mathrm{g} / \mathrm{mL}$ and $4.781 \mu \mathrm{g} / \mathrm{mL}$ after $48 \mathrm{~h}$ and $72 \mathrm{~h}$ treatment; and for RM1 cells, $8.82 \mu \mathrm{g} / \mathrm{mL}$ and $1.045 \mu \mathrm{g} / \mathrm{mL}$ after $48 \mathrm{~h}$ and $72 \mathrm{~h}$ treatment, respectively. Selective cytotoxicity to tumor cells is important, and one of the greatest challenges facing tumor therapy is the inability of anticancer drugs to effectively distinguish between cancer cells and normal cells. We also examined cytotoxicity of CONPs to the normal prostate epithelial cell line RWPE-1, and the $\mathrm{IC}_{50}$ for RWPE-1 cells was $45.997 \mu \mathrm{g} / \mathrm{mL}$ and greater than $45.997 \mu \mathrm{g} / \mathrm{mL}$ after $48 \mathrm{~h}$ and $72 \mathrm{~h}$ of CONP treatment, which indicated that CONPs are selectively cytotoxic to tumor cells (Figure 1A). At the same time, Transwell assays were performed to test whether invasiveness of the tumor cells was inhibited by CONPs in vitro. As shown in Figure 1B, the invasion of PC-3 cells was significantly inhibited by CONPs at concentrations of $1.25 \mu \mathrm{g} / \mathrm{mL}, 2.5 \mu \mathrm{g} / \mathrm{mL}$, and $5 \mu \mathrm{g} / \mathrm{mL}(* P<0.05$, Student's $t$-test $)$.

PC-3 cells are derived from an androgen-negative castration-resistant prostate cancer, which is resistant to endocrine therapy. In addition, annexin V- and PI-based apoptosis and necrosis discrimination assays were performed on PC-3 cells that were exposed to CONPs for $48 \mathrm{~h}$ and $72 \mathrm{~h}$. 
A
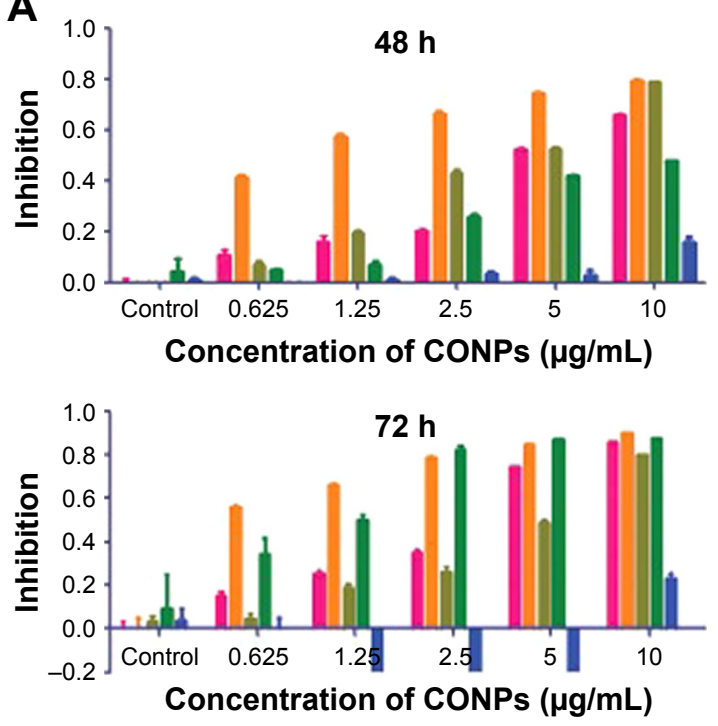

$\square$ PC-3 LNCaP FGC $\square$ DU145 $\square$ RM-1 $\square$ RWPE-1
B

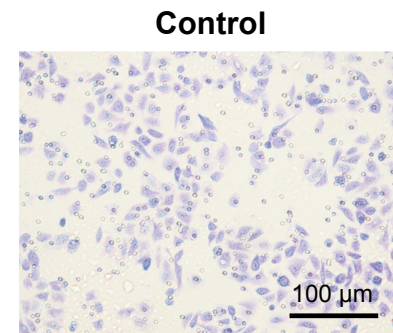

$2.5 \mu \mathrm{g} / \mathrm{mL}$

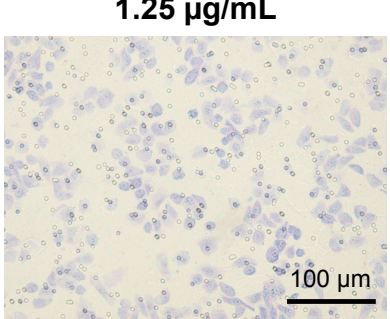

$5 \mu \mathrm{g} / \mathrm{mL}$

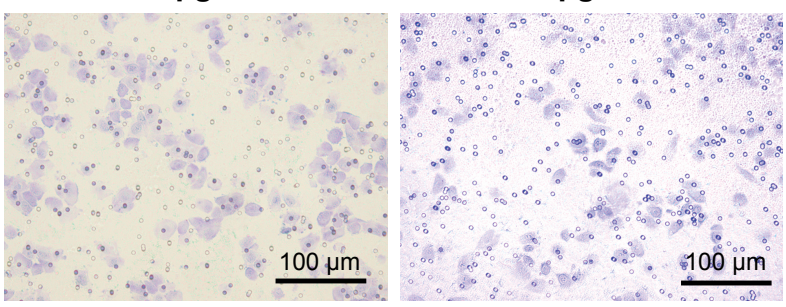

Figure I Cytotoxicity and invasion inhibition effects of CONPs.

Notes: (A) Differential cytotoxicity of CONPs in castration-resistant prostate cancer cells (PC-3, DUI45, RM-I), castration-sensitive prostate cancer cells (LNCaP FGC), and normal cells (RWPE-I) as detected by the CCK8 assay. Prostate cancer cell lines are more sensitive compared with normal prostate epithelial cells. Cells were treated with CONPs for $48 \mathrm{~h}$ and $72 \mathrm{~h}$. (B) Effects of CONPs on the invasion of PC-3 cells. The number of migrating PC-3 cells was obviously decreased after treatment with CONPs for $48 \mathrm{~h}$ in a dose-dependent manner. Magnification 100X.

Abbreviation: CONPs, cuprous oxide nanoparticles.

The results showed that CONPs could significantly induce apoptosis in PC-3 cells in a dose- and time-dependent manner (Figure 3A).

Cell cycle progression analysis was also performed and showed that PC-3 cells were arrested by CONPs in a dosedependent manner. The proliferation of PC-3 cells was significantly inhibited, and approximately $28.34 \%$ and $41.61 \%$ of cells exposed to $5 \mu \mathrm{g} / \mathrm{mL}$ for $48 \mathrm{~h}$ and $72 \mathrm{~h}$, respectively, were arrested at the $\mathrm{G} 2 / \mathrm{M}$ phase after CONPs exposure (Figure 3B and C).

\section{CONPs inhibit the growth of prostate cancer in tumor-bearing mice}

To establish a subcutaneous prostate cancer model, PC-3 cells in the exponential growth phase were subcutaneously transplanted behind the inguen of nude mice. CONPs were dissolved in a $5 \%$ glucose solution using an ultrasonic mixer. When the tumors had grown to an approximate diameter of 5-7 mm, either the CONP solution or a 5\% glucose solution without CONPs (control) was injected into the tumors (this time point was marked as day 0 ). In the CONP treatment group, CONPs were injected at $16 \mathrm{mg} / \mathrm{kg}$ (approximately $400 \mu \mathrm{g}$ CONPs) once per day from day 0 to day 16 . We found that, at each test time point, the tumor volume in all the tumors in the CONP group was lower than that in the tumors of the glucose control group (Figure $2 \mathrm{~A}$ and $\mathrm{B},{ }^{* * *} P<0.001$, Student's $t$-test). In addition, the tumor masses in the CONP group were significantly smaller than the masses recorded for the glucose group at the final time point (Figure $2 \mathrm{C}$ and D, *** $P<0.001$, Student's $t$-test). The weights of the CONPs group were stable, whereas the weight of the mice in the control group decreased a little (Figure 2E). The ratio of $\mathrm{Ki}$-67-positive cells in the CONP group was obviously lower than that in the control group (Figure 2F). In addition, the number of TUNEL-positive cells was higher in the CONP group than in the control, which suggested that CONPs can also induce apoptosis of PC- 3 cells in vivo (Figure 2F). These results showed that the growth of prostate cancer cell was markedly inhibited by CONPs in vivo.

\section{CONPs may attenuate the stemness of prostate cancer cells through the Wnt signaling pathway}

CSCs are one of the challenges for cancer therapy and greatly contribute to drug resistance to chemotherapy and targeted therapy. To test the effects of CONPs on the stemness of PC-3 cells, sphere formation and plate clone formation experiments were performed to explore the selfrenewal and proliferative capacity of PC-3 cells. The sphere formation assay showed that CONPs significantly inhibited 
A

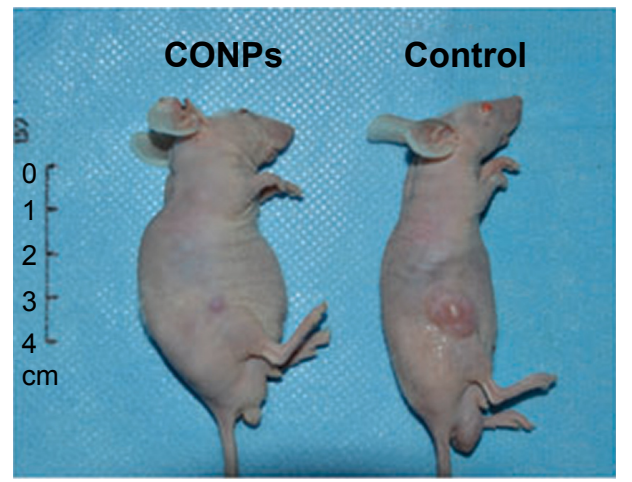

C

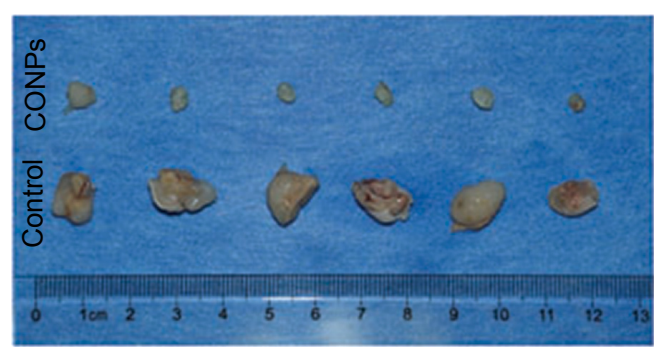

E

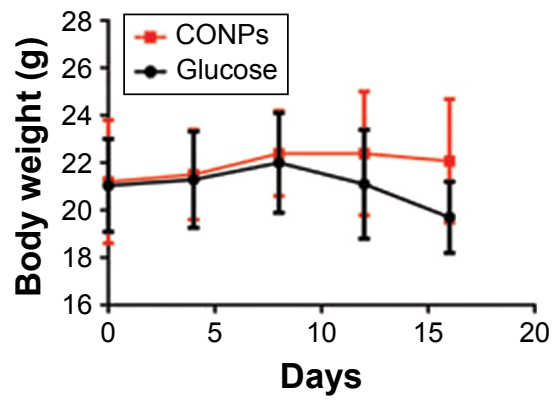

B

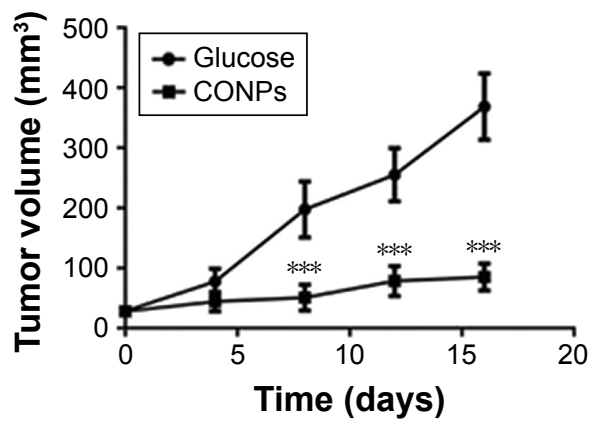

D

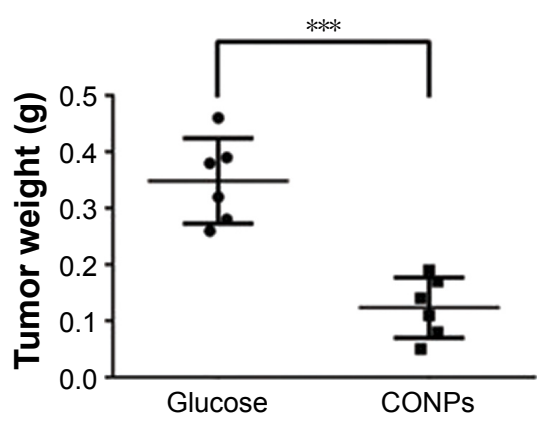

F Ki-67 TUNEL

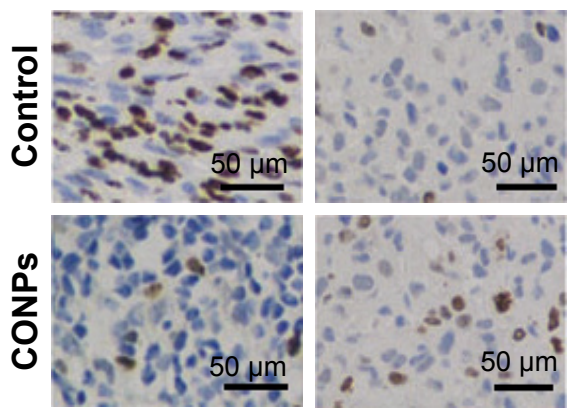

Figure 2 Antitumor effects of CONP therapy on subcutaneous prostate cancer.

Notes: (A) Representative images of mice bearing subcutaneous prostate cancer from the same study on day I4. The tumors from the CONP group were significantly smaller than those from the control group. (B) Plot of tumor volume versus time. Day 0 was the start of the treatment. The mice bearing subcutaneous tumors were euthanized when exhibiting signs of illness or death. The tumor masses from the deceased mice were not included after the day of death. Each group initially contained six mice. The error bars represent \pm SD. The tumors from the CONPs group were significantly smaller compared with the tumors from the control mice $(* * * P<0.00$ I, Student's paired $t$-test, $n=6$ ). (C) Images of excised subcutaneous tumors. The diameters of the subcutaneous tumors from the CONP group were obviously smaller than the diameters observed in tumors from the control group. (D) Statistical analysis of the tumor weight from the CONP and control groups after treatment for 16 days ( $* * * P<0.00 \mathrm{I}$, Student's $t$-test, $n=6$ ). (E) Body weight of mice in the CONPs and control groups. No significant difference in the mouse body weight of two groups was observed. (F) Ki-67 staining and TUNEL staining images. The ratio of Ki-67-positive cells in the CONP group was obviously lower than that in the control group. In addition, the number of TUNEL-positive cells was higher in the CONP group than in the control group. Magnification 200x.

Abbreviations: CONPs, cuprous oxide nanoparticles; TUNEL, terminal deoxynucleotidyl transferase (TdT)-mediated dUTP nick end labeling.

the capacity of sphere formation in a dose-dependent manner (Figure $4 \mathrm{~A}$ and $\mathrm{B}, * * * P<0.001$, ANOVA assay), and there seemed to be no sphere formation at the concentration of $5 \mu \mathrm{g} / \mathrm{mL}$. The plate formation assay also showed similar results, and the clone formation number was significantly decreased by the CONPs (Figure $4 \mathrm{C}$ and $\mathrm{D}, * * * P<0.001$, ANOVA assay), and was also dose-dependent. We also found that CONPs can decrease the expression of Oct4, Sox2, and KLF4, which are important transcription factors for maintaining stemness (Figure 5A). Furthermore, based on the RNA sequencing of renal cancer cells treated with CONPs, CONPs can significantly inhibit the Wnt signaling pathway (unpublished data) (Figure 5B). In addition, the Wnt signaling pathway plays an important role in the maintenance of stemness and participates in the development of prostate CSCs, so we explored the expression levels of genes in the Wnt signaling pathway (including Wnt1A, FZD7, c-Myc, and Cyclin-D1) in PC-3 cells treated with CONPs for $48 \mathrm{~h}$. The Western blot results showed that CONPs can inhibit the gene expression in a dose-dependent manner (Figure 5C). 
A
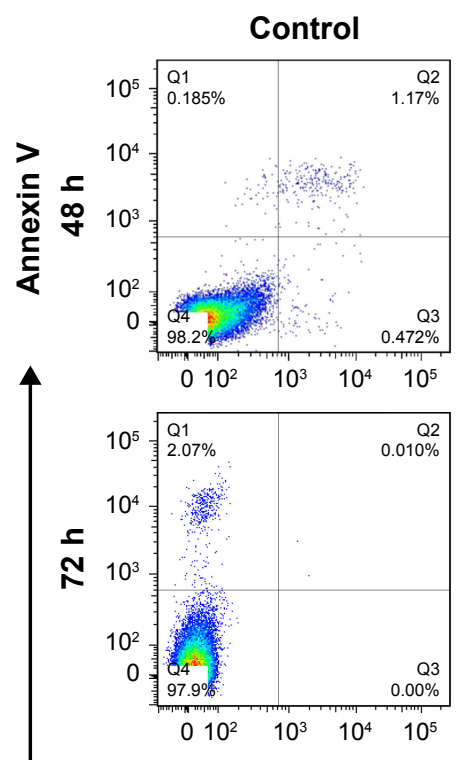

$1.25 \mu \mathrm{g} / \mathrm{mL}$
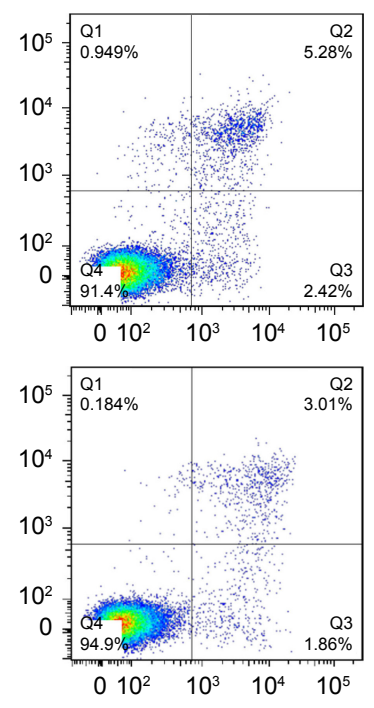

$2.5 \mu \mathrm{g} / \mathrm{mL}$
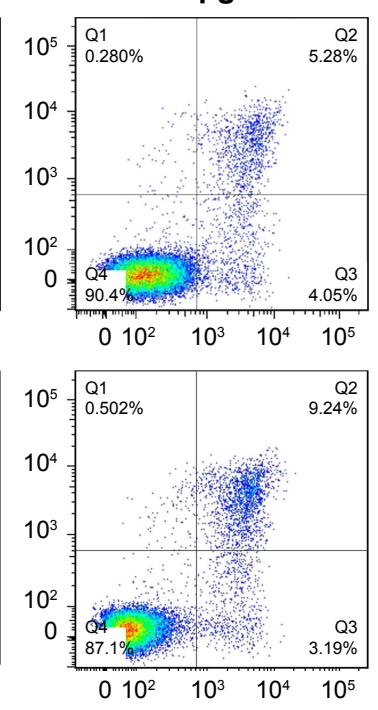
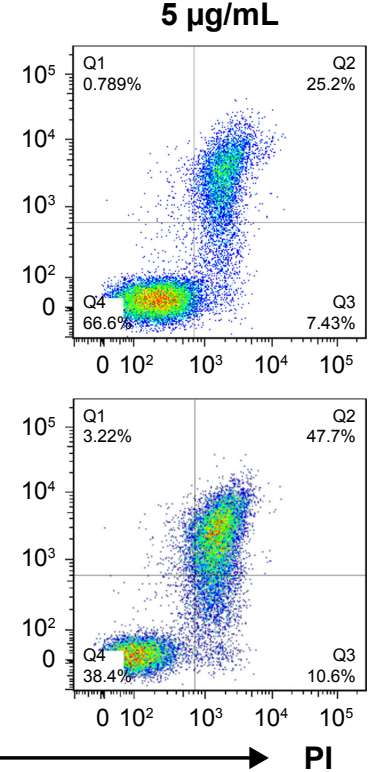

B

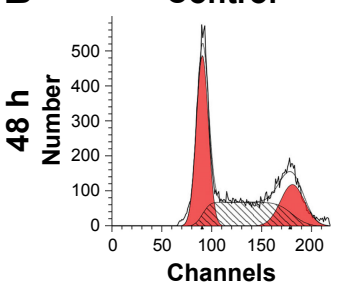

(B3-A-PI/PE-Cy5.5-A)

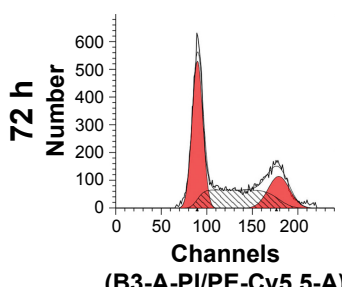

$1.25 \mu \mathrm{g} / \mathrm{mL}$

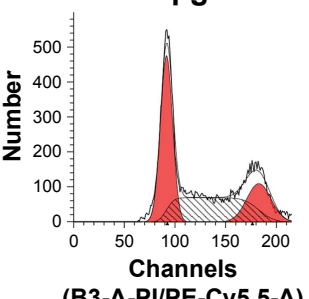

(B3-A-PI/PE-Cy5.5-A)

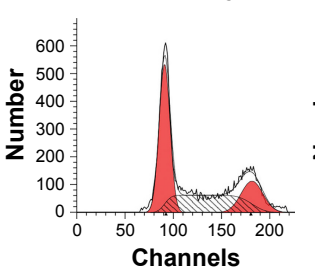

(B3-A-PI/PE-Cy5.5-A)

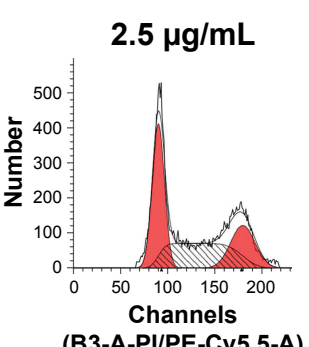

(B3-A-PI/PE-Cy5.5-A)

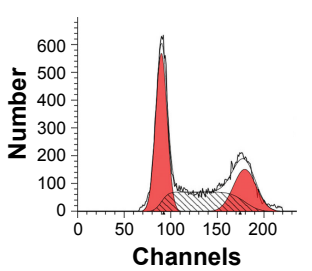

(B3-A-PI/PE-Cy5.5-A)

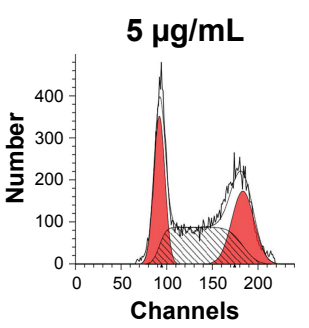

(B3-A-PI/PE-Cy5.5-A)

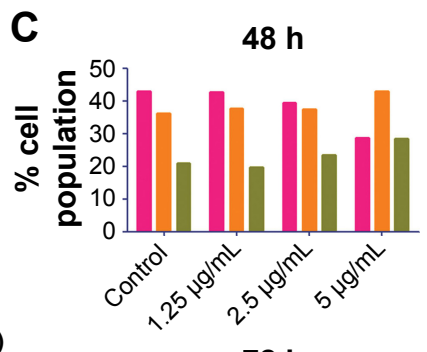

$72 \mathrm{~h}$

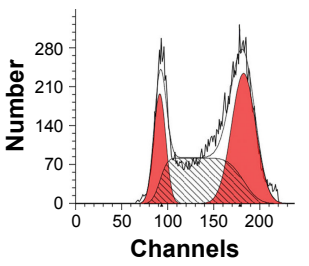

(B3-A-PI/PE-Cy5.5-A)

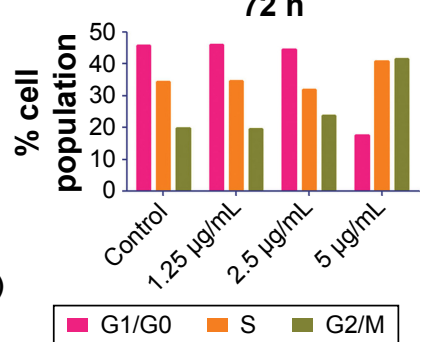

Figure 3 Apoptosis and cell cycle assay.

Notes: (A) Flow cytometry analysis of PC-3 cells treated with different concentrations of CONPs for $48 \mathrm{~h}$ and $72 \mathrm{~h}$, followed by staining with annexin V-FITC and PI. The apoptosis ratio was increased in a dose-dependent manner. (B) Cell cycle progression assay of PC-3 cells treated with different concentrations of CONPs for $48 \mathrm{~h}$ and $72 \mathrm{~h}$. The proliferation of PC-3 cells was strongly suppressed by CONPs in a dose-dependent manner. Cells were arrested in the G2/M phase after $48 \mathrm{~h}$ and $72 \mathrm{~h}$ of treatment and showed a reduced proliferative capacity. (C) Statistics of the cell cycle distribution.

Abbreviation: CONPs, cuprous oxide nanoparticles.

We also found that CONPs can induce autophagy in the PC-3 cells (Figure 5D), which may contribute to apoptosis induction and stemness inhibition.

\section{Discussion}

Cuprous oxide nanoparticles are a type of antitumor inorganic nanomedicine that has shown great potential for cancer therapy. In our previous study, we explored the antimelanoma capacity and systemic toxicity of CONPs in vitro and in vivo. We found that CONPs can selectively induce apoptosis of melanoma cells and have little hepatoxicity and renal toxicity. ${ }^{15,16}$
Asiscommonly known, melanoma with amutated $\mathrm{BRAF}^{\mathrm{V} 600 \mathrm{E}}$ gene requires copper to activate the ERK1/2-mediated signaling pathway, which is important for the rapid proliferation of melanoma. ${ }^{17,22,23}$ The high requirement of copper suggested that blocking copper may be a method that could be used for melanoma therapy. In traditional Chinese medicine, adapting to different requirements in different situations and "give way to the evil gas" are important fundamental ideas for disease treatments. With this mindset, CONPs may exert effects on all cancers that have a high requirement for copper and could be used instead of a copper blocking therapy. 
A

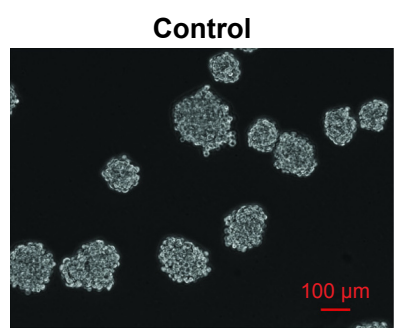

$2.5 \mu \mathrm{g} / \mathrm{mL}$
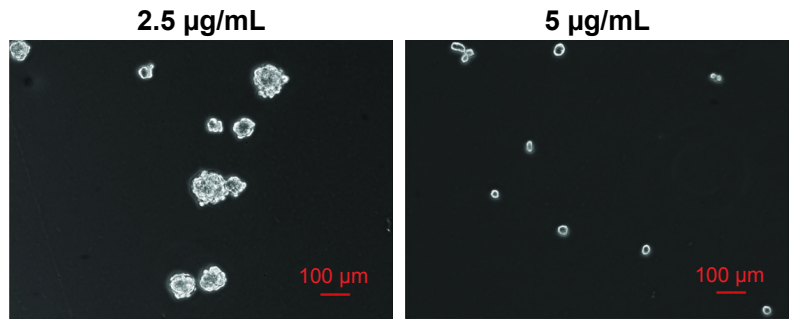

C
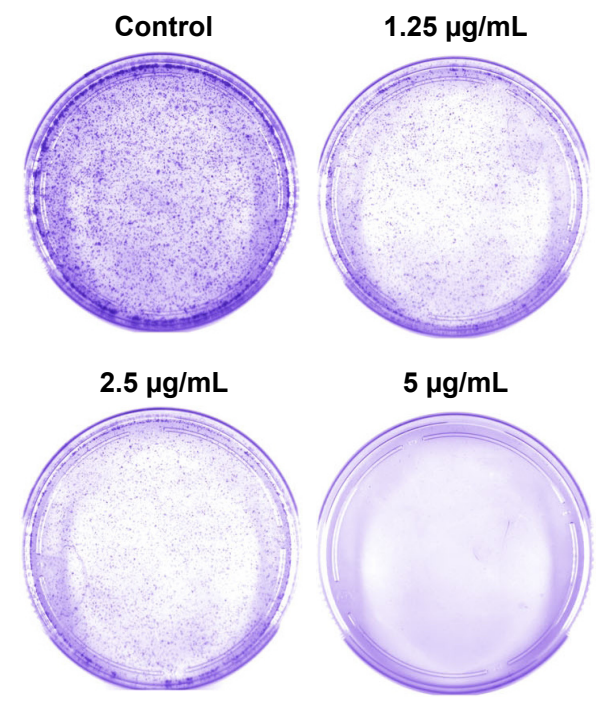

$1.25 \mu \mathrm{g} / \mathrm{mL}$

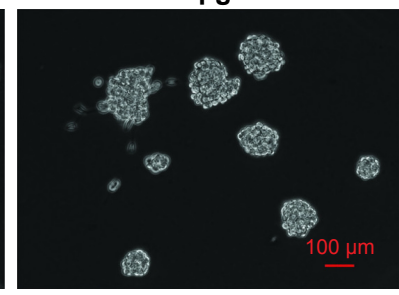

$5 \mu \mathrm{g} / \mathrm{mL}$

$1.25 \mu \mathrm{g} / \mathrm{mL}$

$5 \mu \mathrm{g} / \mathrm{mL}$

Figure 4 CONPs attenuated the stemness of prostate cancer cells.

Notes: (A) Image of prostate cancer cell spheres treated with CONPs at different concentrations. (B) Statistical analysis of the number of spheres formed. The number was significantly decreased by CONPs treatment in a dose-dependent manner (***P<0.00I, ANOVA assay). (C) Image of plate clone formation of prostate cancer treated with CONPs at different concentrations. (D) Statistical analysis of the number of plate clones formed. The number was significantly decreased by CONPs treatment in a dose-dependent manner (***P<0.00I, ANOVA assay).

Abbreviation: CONPs, cuprous oxide nanoparticles.

Because prostate cancer also requires copper, as does melanoma, we speculated that prostate cancer may also be sensitive to CONPs. In this study, we first explored the cytotoxicity of CONPs in prostate cancer cell lines in vitro. The results showed that all the prostate cancer cell lines were sensitive to CONPs in a dose- and time-dependent manner and that the normal prostate epithelial cell line RWPE1 cell was highly tolerant to CONPs, which suggested that CONPs are selectively cytotoxic to prostate cancer cells. CONPs can induce apoptosis and cause cell cycle arrest at the G2/M phase. The subcutaneous prostate cancer mice model study indicated that CONPs showed ideal antitumor capacity, could inhibit the proliferation, and could induce apoptosis of

\section{B}

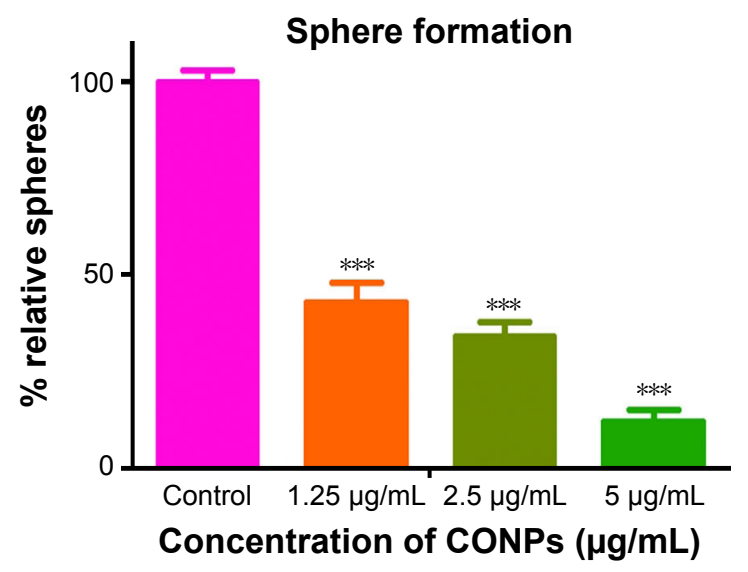

D

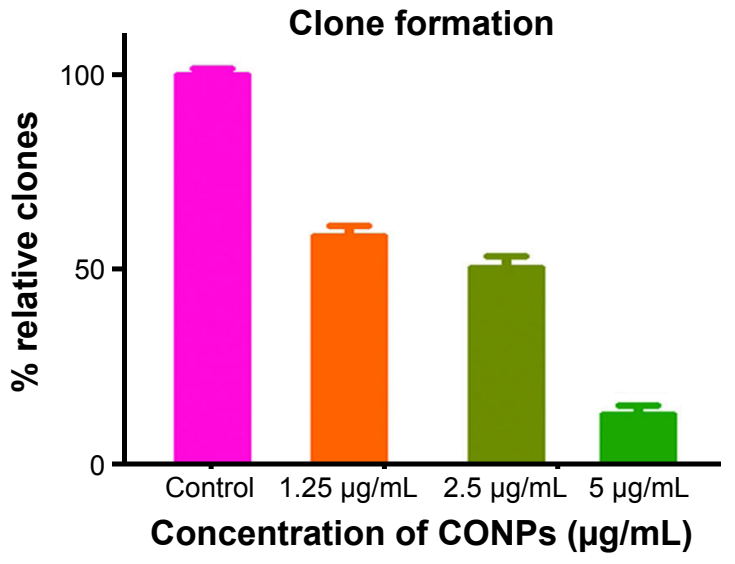

prostate cancer cells based on the Ki-67 staining and TUNEL staining results.

As is commonly known, CSCs play an important role in the progression and development of various cancers. ${ }^{24}$ Prostate CSCs also participate in bone metastasis, castration resistance, radiotherapy resistance, and other types of cancer developmental progressions. ${ }^{25-27}$ Therefore, it is important for us to identify new drugs that can target prostate CSCs or attenuate the stemness of prostate cancer cells.

To explore the effects of CONPs on the stemness of PC-3 cells, sphere formation and clone formation assays were performed. We found that CONPs can significantly inhibit sphere formation and clone formation, which suggested 
A

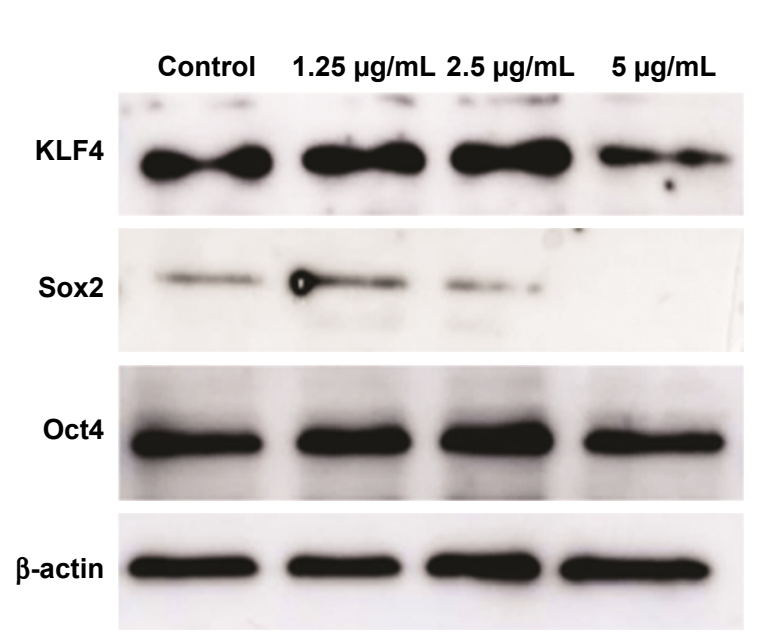

B
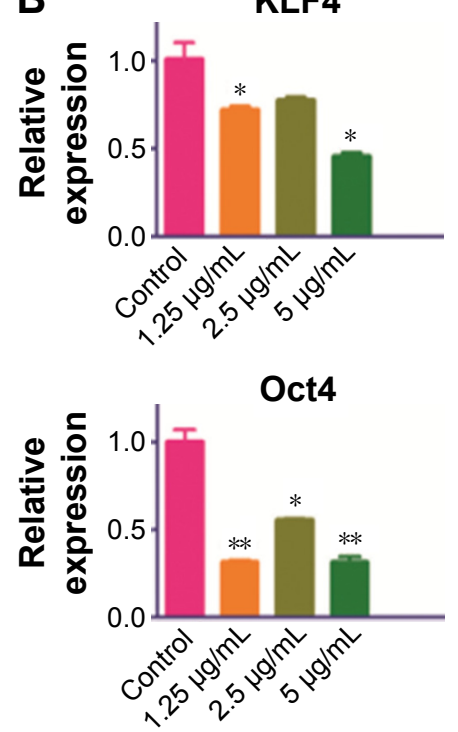

Sox2
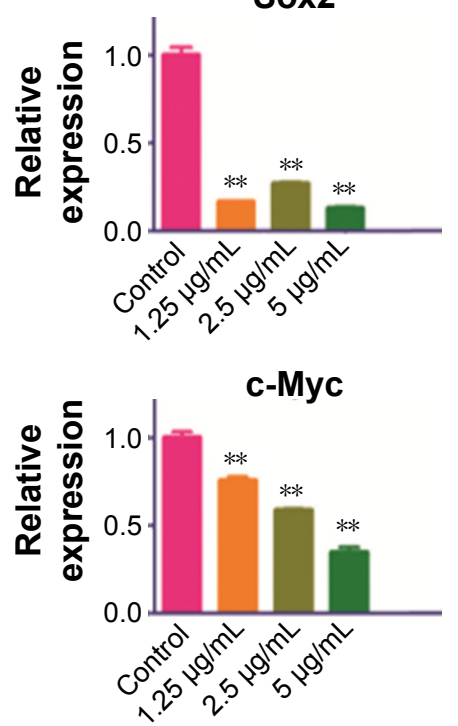

C
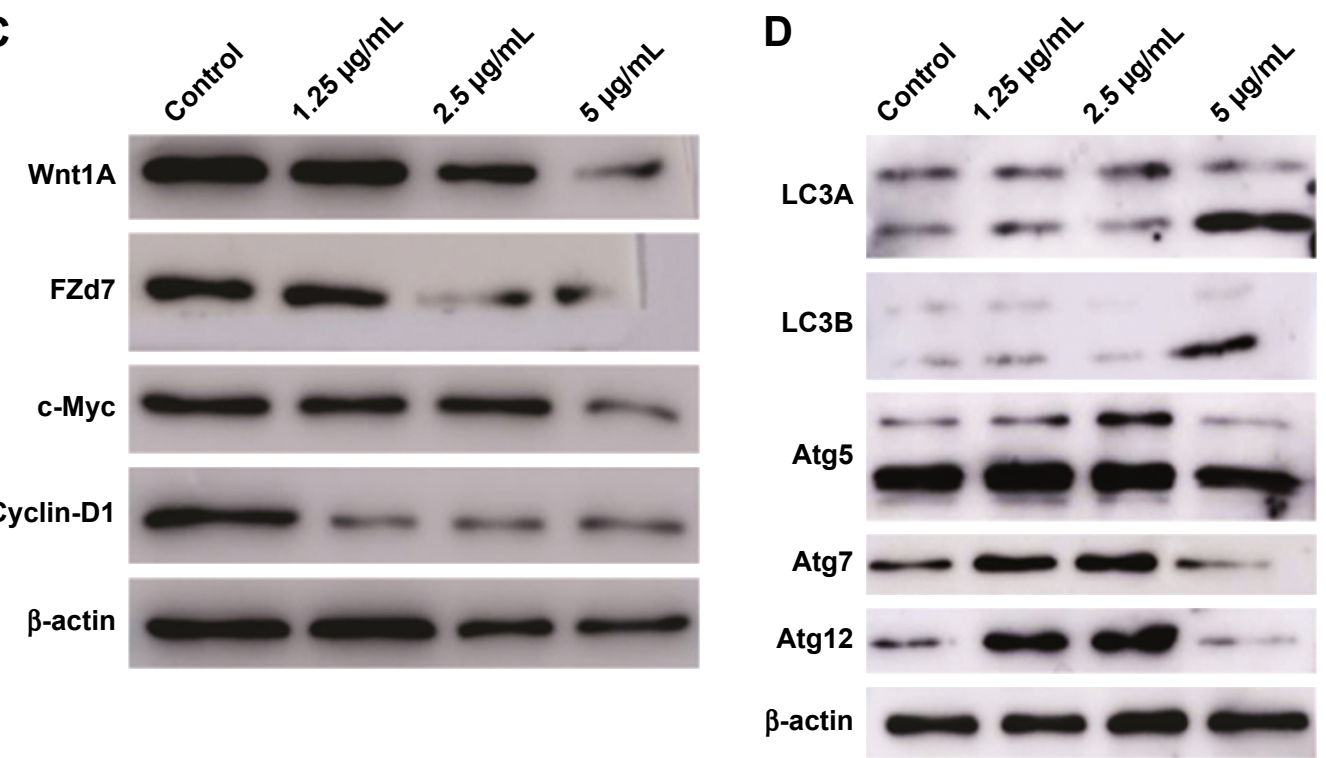

Figure 5 CONPs inhibited stemness and the activation of the Wnt signaling pathway of prostate cancer.

Notes: (A) Western blot assay of KLF4, Sox2, and Oct4 in PC-3 cells treated with CONPs at different concentrations for 48 h. KLF4, Sox2, and Oct4 were downregulated after treatment with CONPs, especially at the concentration of $5 \mu \mathrm{g} / \mathrm{mL}$. (B) qRT-PCR assay of KLF4, Sox2, Oct4, and c-Myc in PC-3 cells treated with CONPs at different concentrations for $48 \mathrm{~h}$. The expression levels of KLF4, Sox2, Oct4, and c-Myc in PC-3 cells were downregulated after CONP treatment (*P<0.05, $* * P<0.0 \mathrm{I}$, ANOVA assay). (C) Western blot assay of genes in the Wnt signaling pathway in PC-3 cells treated with CONPs at different concentrations for 48 h. Wnt IA, FZD7, c-Myc, and Cyclin-DI protein levels were downregulated by CONPs after $48 \mathrm{~h}$. (D) Western blot assay of autophagy signaling in PC-3 cells treated with CONPs at different concentrations for $48 \mathrm{~h}$. LC3A, LC3B, and Atg5 were upregulated at all the CONP concentrations tested. Atg7 and Atg 12 were upregulated at concentrations of $1.25 \mu \mathrm{g} / \mathrm{mL}$ and $2.5 \mu \mathrm{g} / \mathrm{mL}$ but were downregulated at the concentration of $5 \mu \mathrm{g} / \mathrm{mL}$.

Abbreviation: CONPs, cuprous oxide nanoparticles.

that CONPs can interfere with the self-renewal capacity of prostate CSCs. Western blotting found that CONPs can downregulate the expression of KLF4, Sox2, and Oct4, which are important for stemness maintenance. ${ }^{28-30}$

The Wnt signaling pathway is one of the important signaling pathways for maintaining stemness. ${ }^{31,32}$ Therefore, we tried to determine whether CONPs can influence Wnt signaling. Western blot and qRT-PCR results indicated that CONPs can inhibit the expression of genes involved in Wnt signaling such as Wnt1A, FZD7, c-Myc, and Cyclin-D1, which can explain why CONPs can attenuate the stemness of prostate cancer cells and cause cell cycle arrest.

In this study, we determined the antiprostate cancer capacity of CONPs using human prostate cancer cell lines in vitro and in vivo. CONPs can selectively induce apoptosis in prostate cancer cells, cause cycle arrest, and inhibit the migration and invasion of these cells in vitro. CONPs can also inhibit the growth of prostate cancer in a subcutaneous 
mouse model. More importantly, CONPs can attenuate the stemness of prostate cancer cells, and blocking the Wnt signaling pathway may contribute to the therapeutic effects of CONPs, which suggested that CONPs have great potential as a castration-resistant prostate cancer therapy. In our further research, we will focus on the translational research to explore the potential clinical use of CONPs, and perform the systemic toxicology and pharmacokinetics research. At the same time, we will also try to explore the potential target protein or other molecules, and put forward the mechanism of research.

\section{Acknowledgments}

This work was supported by the National Natural Science Foundation of China (Grant numbers 81472771) and the Basic Research Key Foundation of Shanghai (Grant number 13JC1401402). We thank Chuanliang Xu of the Department of Urology for his helpful discussions.

\section{Disclosure}

The authors report no conflicts of interest in this work.

\section{References}

1. Falchook AD, Basak R, Chen RC. Androgen deprivation therapy and dose-escalated radiotherapy for intermediate- and high-risk prostate cancer-reply. JAMA Oncol. 2017;3(2):280-281.

2. Rajan P, Sudbery IM, Villasevil ME, et al. Next-generation sequencing of advanced prostate cancer treated with androgen-deprivation therapy. Eur Urol. 2014;66(1):32-39.

3. Cooperberg MR, Hinotsu S, Namiki M, Carroll PR, Akaza H. TransPacific variation in outcomes for men treated with primary androgendeprivation therapy (ADT) for prostate cancer. BJU Int. 2016;117(1): 102-109.

4. Albertsen P. Androgen deprivation in prostate cancer - step by step. N Engl J Med. 2009;360(24):2572-2574.

5. Nguyen PL, Alibhai SM, Basaria S, et al. Adverse effects of androgen deprivation therapy and strategies to mitigate them. Eur Urol. 2015; 67(5):825-836.

6. Bernemann C, Schnoeller TJ, Luedeke M, et al. Expression of AR-V7 in circulating tumour cells does not preclude response to next generation androgen deprivation therapy in patients with castration resistant prostate cancer. Eur Urol. 2017;71(1):1-3.

7. Jones CU, Hunt D, McGowan DG, et al. Radiotherapy and short-term androgen deprivation for localized prostate cancer. $N$ Engl J Med. 2011;365(2):107-118.

8. Beer TM, Armstrong AJ, Rathkopf DE, et al. Enzalutamide in metastatic prostate cancer before chemotherapy. N Engl J Med. 2014;371(5): 424-433.

9. Body JJ, Casimiro S, Costa L. Targeting bone metastases in prostate cancer: improving clinical outcome. Nat Rev Urol. 2015;12(6):340-356.

10. Gupta S, Li J, Kemeny G, Bitting RL, et al. Whole genomic copy number alterations in circulating tumor cells from men with abiraterone or enzalutamide resistant metastatic castration-resistant prostate cancer. Clin Cancer Res. Epub 2016 Sep 06.

11. Chen SJ, Chen Z. Targeting agents alone to cure acute promyelocytic leukemia. $N$ Engl J Med. 2013;369(2):186-187.
12. Zhang XW, Yan XJ, Zhou ZR, et al. Arsenic trioxide controls the fate of the PML-RARalpha oncoprotein by directly binding PML. Science. 2010;328(5975):240-243.

13. Youyou T, Muyun N, Yurong Z, et al. Studies on the constituents of artemisia annual. Yao Xие Xие Bao. 2015;50(10):366-370. Chinese.

14. Brown GD. The biosynthesis of artemisinin (Qinghaosu) and the phytochemistry of Artemisia annua L. (Qinghao). Molecules. 2010; 15(11):7603-7698.

15. Wang Y, Zi XY, Su J, et al. Cuprous oxide nanoparticles selectively induce apoptosis of tumor cells. Int J Nanomedicine. 2012;7: 2641-2652.

16. Wang Y, Yang F, Zhang HX, et al. Cuprous oxide nanoparticles inhibit the growth and metastasis of melanoma by targeting mitochondria. Cell Death Dis. 2013;4:e783.

17. Brady DC, Crowe MS, Turski ML, et al. Copper is required for oncogenic BRAF signalling and tumorigenesis. Nature. 2014;509(7501): 492-496.

18. Thoma C. Prostate cancer: copper unlocks therapeutic potential of disulfiram. Nat Rev Urol. 2014;11(12):664.

19. Safi R, Nelson ER, Chitneni SK, et al. Copper signaling axis as a target for prostate cancer therapeutics. Cancer Res. 2014;74(20):5819-5831.

20. Sarveswaran S, Varma N, Morisetty S, Ghosh J. Inhibition of 5-lipoxygenase downregulates stemness and kills prostate cancer stem cells by triggering apoptosis via activation of c-Jun N-terminal kinase. Oncotarget. Epub 2016 Nov 17.

21. Liu N, Mei L, Fan X, et al. Phosphodiesterase 5/protein kinase G signal governs stemness of prostate cancer stem cells through Hippo pathway. Cancer Lett. 2016;378(1):38-50.

22. Devji T, Levine O, Neupane B, Beyene J, Xie F. Systemic therapy for previously untreated advanced BRAF-mutated melanoma: a systematic review and network meta-analysis of randomized clinical trials. JAMA Oncol. Epub 2016 Oct 27.

23. Hirata E, Girotti MR, Viros A, et al. Intravital imaging reveals how BRAF inhibition generates drug-tolerant microenvironments with high integrin $\beta 1 /$ FAK signaling. Cancer Cell. 2015;27(4):574-588.

24. Shackleton M, Quintana E, Fearon ER, Morrison SJ. Heterogeneity in cancer: cancer stem cells versus clonal evolution. Cell. 2009; 138(5):822-829.

25. Schubbert S, Jiao J, Ruscetti M, et al. Methods for PTEN in Stem Cells and Cancer Stem Cells. Methods Mol Biol. 2016;1388:233-285.

26. Luo J, Ok Lee S, Liang L, et al. Infiltrating bone marrow mesenchymal stem cells increase prostate cancer stem cell population and metastatic ability via secreting cytokines to suppress androgen receptor signaling. Oncogene. 2014;33(21):2768-2778.

27. Collins AT, Berry PA, Hyde C, Stower MJ, Maitland NJ. Prospective identification of tumorigenic prostate cancer stem cells. Cancer Res. 2005;65(23):10946-10951.

28. Soufi A, Donahue G, Zaret KS. Facilitators and impediments of the pluripotency reprogramming factors' initial engagement with the genome. Cell. 2012;151(5):994-1004.

29. Macfarlan TS, Gifford WD, Driscoll S, et al. Embryonic stem cell potency fluctuates with endogenous retrovirus activity. Nature. 2012; 487(7405):57-63.

30. Heallen T, Zhang M, Wang J, et al. Hippo pathway inhibits Wnt signaling to restrain cardiomyocyte proliferation and heart size. Science. 2011; 332(6028):458-461.

31. Cojoc M, Peitzsch C, Kurth I, et al. Aldehyde dehydrogenase is regulated by $\beta$-catenin/tcf and promotes radioresistance in prostate cancer progenitor cells. Cancer Res. 2015;75(7):1482-1494.

32. Acevedo VD, Gangula RD, Freeman KW, et al. Inducible FGFR-1 activation leads to irreversible prostate adenocarcinoma and an epithelialto-mesenchymal transition. Cancer Cell. 2007;12(6):559-571. 
International Journal of Nanomedicine

Dovepress

\section{Publish your work in this journal}

The International Journal of Nanomedicine is an international, peerreviewed journal focusing on the application of nanotechnology in diagnostics, therapeutics, and drug delivery systems throughout the biomedical field. This journal is indexed on PubMed Central, MedLine, CAS, SciSearch ${ }^{\circledR}$, Current Contents ${ }^{\circledR} /$ Clinical Medicine,
Journal Citation Reports/Science Edition, EMBase, Scopus and the Elsevier Bibliographic databases. The manuscript management system is completely online and includes a very quick and fair peer-review system, which is all easy to use. Visit http://www.dovepress.com/ testimonials.php to read real quotes from published authors.

Submit your manuscript here: http://www.dovepress.com/international-journal-of-nanomedicine-journal 